\title{
Comprehensive analysis of fibroblast growth factor receptor expression patterns during chick forelimb development
}

\author{
CAROLINE J. SHEEBA ${ }^{1}$, RAQUEL P. ANDRADE ${ }^{1}$, DELPHINE DUPREZ² and ISABEL PALMEIRIM*,3,4 \\ ${ }^{1}$ Life and Health Sciences Research Institute (ICVS), School of Health Sciences, University of Minho, Braga, Portugal, \\ ${ }^{2}$ Biologie Moléculaire et Cellulaire du Développement, Université Pierre et Marie Curie, Paris, France, ${ }^{3}$ Regenerative \\ Medicine Program, Departamento de Ciências Biomédicas e Medicina, Universidade do Algarve and ${ }^{4}$ Institute for Biotech- \\ nology and Bioengineering, Centro de Biomedicina Molecular e Estrutural, Universidade do Algarve, Faro, Portugal
}

\begin{abstract}
Specific interactions between fibroblast growth factors (Fgf1-22) and their tyrosine kinase receptors (FgfR1-4) activate different signalling pathways that are responsible for the biological processes in which Fgf signalling is implicated during embryonic development. In the chick, several Fgf ligands (Fgf2, 4, 8, 9, 10, 12, 13 and 18 ) and the four FgfRs (FgfR 1, 2, 3 and 4) have been reported to be expressed in the developing limb. The precise spatial and temporal expression of these transcripts is important to guide the limb bud to develop into a wing/leg. In this paper, we present a detailed and systematic analysis of the expression patterns of FgfR1, 2, 3 and 4 throughout chick wing development, by in situ hybridisation on whole mounts and sections. Moreover, we characterize for the first time the different isoforms of FGFR1-3 by analysing their differential expression in limb ectoderm and mesodermal tissues, using RT-PCR and in situ hybridisation on sections. Finally, isoform-specific sequences for FgfR1IIIb, FgfR1IIIc, FgfR3IIIb and FgfR3IIIc were determined and deposited in GenBank with the following accession numbers: GU053725, GU065444, GU053726, GU065445, respectively.
\end{abstract}

KEY WORDS: Fgf, FgfRs, limb, chick

The developing chick limb grows out as a protrusion of mesenchymal cells from the lateral plate mesoderm and adjacent somites. Cells from the lateral plate mesoderm form cartilage and connective tissues, such as muscle sheaths, tendons and ligaments. Meanwhile, myogenic precursor cells delaminate from the lateral part of the somites, migrate to the limb bud, colonise the dorsal and ventral limb regions and activate the myogenic program to differentiate into multinucleated myotubes, thus generating the definitive limb skeletal muscles (Christ and Brand-Saberi, 2002; Duprez, 2002; Buckingham et al. 2003). The mesenchyme of the limb bud is enveloped by an ectodermal jacket, whose distal tip forms a specialised epithelial structure, the apical ectodermal ridge (AER) (Todt and Fallon, 1984). Mesenchymal cells directly under the AER remain undifferentiated and populate the so-called undifferentiated zone (Tabin and Wolpert, 2007). Condensation of the cartilage elements proceeds in a proximal to distal direction based on cells' temporal and positional values, which could be provided by the reported limb molecular clock (Pascoal et al. 2007a; reviewed in Pascoal and Palmeirim, 2007; Tabin and Wolpert, 2007).
During development, changes occur along the three limb bud axes - anterior-posterior (AP), dorsal-ventral (DV) and proximaldistal (PD) - conducted by three distinct signalling centres, the zone of polarizing activity (ZPA), the dorsal (non-ridge) ectoderm and the AER, respectively (reviewed in Towers and Tickle, 2009). ZPA activity is mediated by the diffusible molecule Sonic hedgehog (Shh) (reviewed in Towers and Tickle, 2009). The DV axis is specified by the signalling molecule Wnt-7a and the transcription factor Lmx1b, which are expressed in the dorsal limb ectoderm and dorsal mesenchyme, respectively (Parr and McMahon, 1995; Chen et al. 1998). Wnt-7a expression is repressed in the ventral ectoderm by Engrailed1, a target of Bmp signalling (Loomis et al. 1996). The AER drives PD limb outgrowth (Saunders, 1948) and its activity is mediated by several fibroblast growth factor (Fgf) family members (Niswander et al. 1993; Fallon et al. 1994), whose

Abbreviations used in this paper: AER, apical ectodermal ridge; Fgf, fibroblast growth factor; FgfR, Fgf receptor; ZPA, zone of polarizing activity.

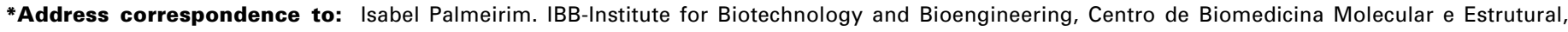

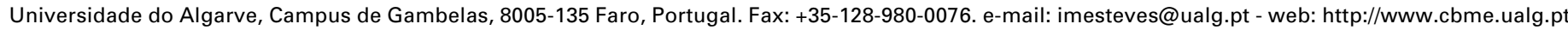


sequential contribution to PD limb growth over time has been recently reported (Mariani et al. 2008). Fgfs comprise several structurally related polypeptides, many of which have been described to be expressed in the developing chick limb (Fallon et al. 1994; Savage and Fallon, 1995; Crossley et al. 1996; Ohuchi et al. 1997; Munoz-Sanjuan et al. 1999; Ohuchi et al. 2000; Havens et al. 2006). The expression of Fgf4, 8 and 9 is restricted to the AER, Fgf10, 12, 13 and 18 are expressed in the limb mesenchyme and Fgf2 is expressed both in the ectoderm, including the $\mathrm{AER}$, and in the mesenchyme. Fgf4 is also expressed in muscle from E6 (Edom-Vovard et al. 2001a) and Fgf8 in tendons from E8

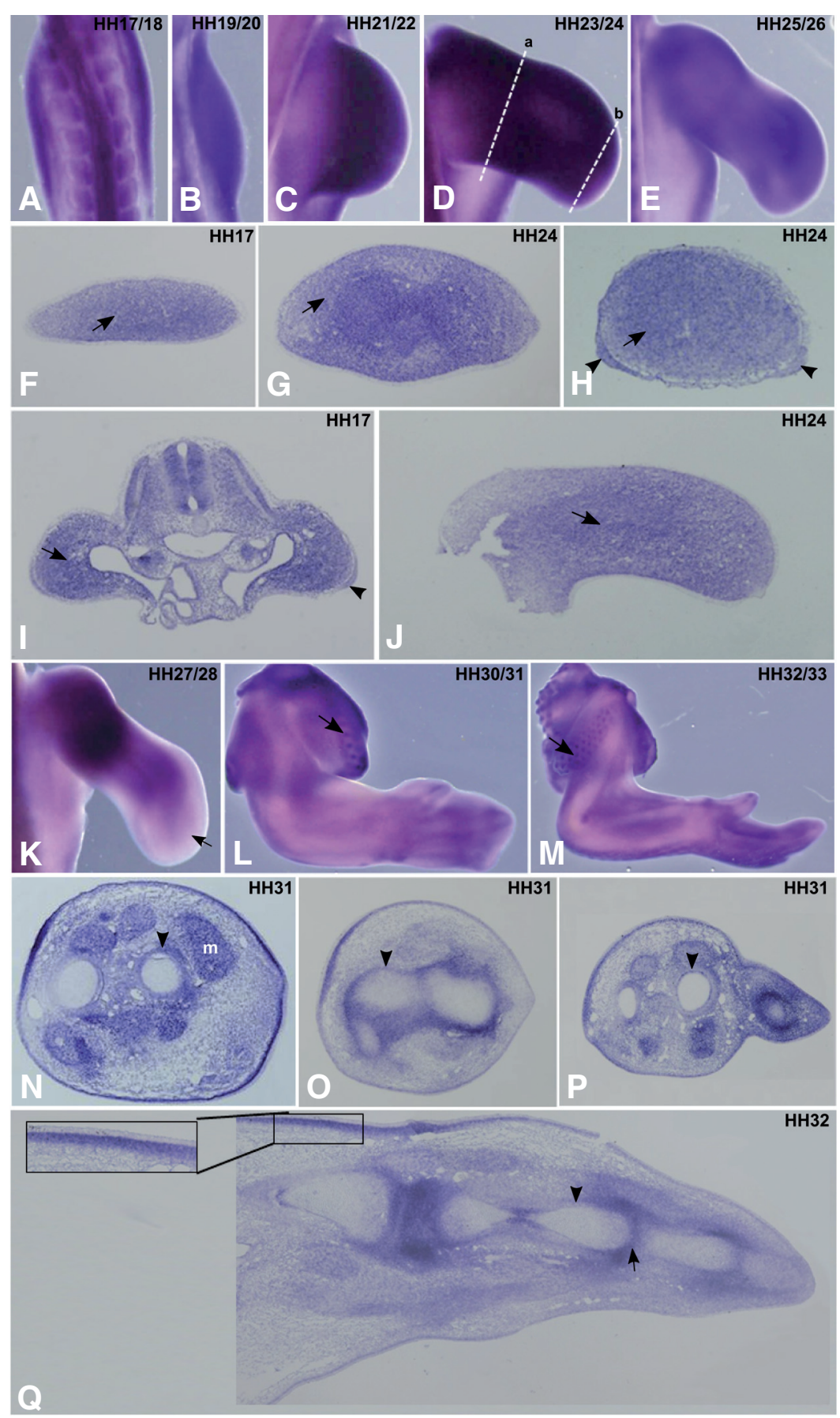

(Edom-Vovard et al. 2001b). Fgf4 and 8, however, are indispensable for limb development, since targeted deletion of Fgf4 and Fgf 8 in the AER generated limbless mice (Sun et al. 2002; Boulet et al., 2004). AER-derived Fgfs signal to the underlying mesenchyme, which is evidenced by the distal to proximal gradient of the Fgf8 effector Mkp3 (Pascoal et al. 2007b), maintaining the subjacent mesoderm in an undifferentiated, proliferative state (Tabin and Wolpert, 2007).

Fgf signalling is implicated in many biological processes during development, such as differentiation, proliferation (Prykhozhij and Neumann, 2008), survival, migration, adhesion, apoptosis and chemotaxis (reviewed in Bottcher and Niehrs, 2005). All Fgfs mediate their cellular responses by binding to and activating appropriate Fgf receptors (FgfRs), which belong to a family of cell surface receptor tyrosine kinases. FgfRs contain an extracellular Fgf binding domain composed of three immunoglobulinlike domains, a transmembrane domain and an intracellular tyrosine kinase domain. There are four known FgfRs and among these, FgfR1-3 can generate alternatively spliced isoforms (reviewed in Eswarakumar et al. 2005) that display different ligand specificity (Ornitz et al. 1996; Zhang et al. 2006). Ligand binding in the presence of heparan sulfate proteoglycans leads to receptor dimerisation and activation of downstream intracellular signalling cascades, such as Ras-MAP kinase, PI3 kinase/Akt and PLC gamma/PKC (reviewed in Dailey et al. 2005). When mutated or misexpressed, Fgfs and their receptors cause morphogenic disorders affecting limb formation and can

Fig. 1. FgfR1 expression pattern during chick forelimb development. Chick wings at HH17-33 stages were processed for in situ hybridisation in whole-mounts (A-E, K-M) and in transversal/longitudinal sections (F-J, N-Q) using a probe for non isoform-specific chick FgfR1. (A-E) In situ hybridisation in whole-mount limbs for FgfR1 showed a generalized expression in limb mesenchyme. (F-H) Transverse sections of limb buds at HH17 and HH24 (G: proximal, H: distal, represented in (D) as (a) and (b), respectively) show FgfR1 expression in the limb mesenchyme (arrows), and in the ectoderm of the distal limb (H, arrowheads). (I,J) Longitudinal limb sections at HH17 and HH24 show FgfR1 expression in the limb mesenchyme (arrows), and in the AER of HH17 limb bud (I, arrowhead). (K) In situ hybridisation in whole-mount limbs at HH27/28 stage show decreasednFgfR1 expression in the distal limb mesenchyme (arrow). (L,M) FgfR1 expression is observed in developing feather buds of the body wall (arrows). (N-P) Transverse sections of forelimb at stage HH31 show FgfR1 expression in perichondrium (arrowheads) and in muscles (m). (Q) In situ hybridisation in longitudinal limb sections at HH32 shows that FgfR1 transcripts are observed in the perichondrium (arrowhead) and in the future interphalangic joints (arrow). The inset in (Q) shows an upregulation of FgfR1 expression in the mesenchyme close to the proximal ectoderm. (A-E, K-M) are dorsal views of whole-mount limbs. (F-H, N-P) Transverse sections are oriented such that left - posterior, right - anterior, top dorsal and bottom - ventral. (I,J, $\mathbf{Q})$ longitudinal limb sections are positioned such that left - proximal and right - distal. Embryonic stages of the limbs are mentioned in the upper right corner of the pictures. 
also lead to cancer (reviewed in Wilkie et al. 2002; Eswarakumar et al. 2005).

The expression pattern of FgfR 1-4 on sections during chick limb development has been previously reported to some extent (Marcelle et al. 1995; Szebenyi et al. 1995; Eloy-Trinquet et al. 2009). Nevertheless, as our knowledge on the importance of Fgf signalling in limb development increased considerably over the last decade, a more detailed description of the spatial and temporal distribution of all FgfRs became compulsory. Moreover, very little is known about FGFR isoform-specific expression during limb development. Although there are studies available for the expression pattern of FgfR2IIlb and FgfR2IIlc isoforms (Lizarraga et al. 1999; Havens et al. 2006), knowledge on the expression of the FgfR1 and FgfR3 isoforms is lacking, in both chick and mouse. We hereby report
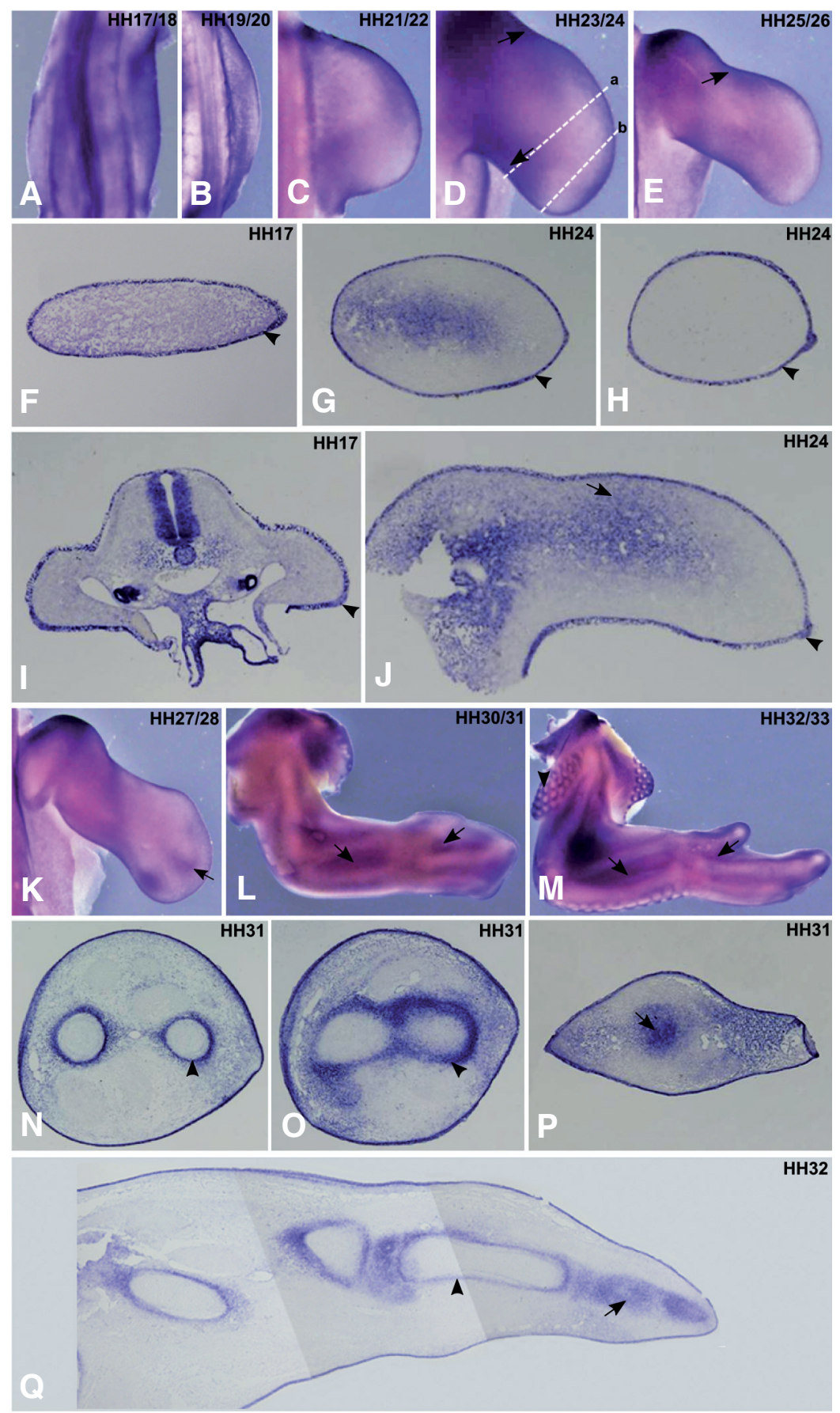

comprehensive expression analyses of FgfR1-4 and IIIb and IIlc isoforms of FgfR1-3 during chick forelimb bud development, from stage $\mathrm{HH} 17$ to $\mathrm{HH} 33$ (Hamburger and Hamilton, 1951), using RT-PCR and in situ hybridisation on whole mount and sections.

\section{Results}

This work presents a comprehensive analysis of the expression patterns of FgfR 1-4 during chick forelimb development in stages $\mathrm{HH} 17$ through $\mathrm{HH} 33$ by in situ hybridization. For each receptor, a non isoform-specific probe was used allowing an overall visualization of expression spatial distribution. Subsequently, we analysed the expression of the IIIb and IIIC isoforms of FgfR 1-3 by RT-PCR and in situ hybridisation on sections.

\section{FgfR1 expression}

Between stages $\mathrm{HH} 17$ and $\mathrm{HH} 26$, FgfR1 is expressed along the entire PD axis of the chick limb bud (Fig. 1A-E). Transverse and longitudinal section analyses show that FgfR1 transcripts are present mainly in the mesenchyme (Fig. $1 \mathrm{~F}-\mathrm{J}$, arrows) and are absent from the enveloping ectoderm in the proximal part of the limb. In the distal limb, however, FgfR1 is also observed in sections in the distal ectoderm, including the AER (Fig. $1 \mathrm{H}, \mathrm{I}$, arrowhead). At stage $\mathrm{HH} 26$, when cartilage differentiation is in progress, FgfR1 transcripts are detected throughout the limb, although in a slightly graded proximal to distal distribution (Fig. 1E, data not

Fig. 2. FgfR2 expression pattern during chick forelimb development. Chick wings at HH17-33 stages were processed for in situ hybridisation in whole-mounts (A-E, K-M) and transverse/longitudinal sections (F-J, $\mathbf{N}-\mathbf{Q}$ ) using a probe for non isoform specific chick FgfR2. (A-E) In situ hybridisation in whole mount limbs using the FgfR2 probe showed its presence in the limb ectoderm, including the AER. (F-H) Transverse limb sections (G: proximal, H: distal, represented in (D) as (a) and (b), respectively) confirm the ectodermal expression of FgfR2 (arrowheads), although a faint proximal) posterior mesenchymal expression could also be observed at HH24 (G, arrow). (I,J) Longitudinal limb sections at HH17 and HH24 show'FgfR2 expression in the ectoderm (arrowheads) including the AER and also in the mesenchyme (arrow). (K-M) In situ hybridisation in whole-mount limbs show FgfR2 expression in between the zeugopod skeletal elements and in the interdigital zones (arrows) and around the feather buds in the body wall (M, arrowhead). (N-P) Transverse sections of forelimb at stage HH31 show FgfR2nexpression in perichondrium (arrowheads) and in the entire distal cartilage element (arrow). (Q) In situ hybridisation in longitudinal limb sections at HH32 show FgfR2 expression in distal cartilage elements (arrow) and in perichondrium in more proximal cartilage elements (arrowhead). (A-E, K-M) are dorsal views of wholemount limbs. (F-H, N-P) transverse sections are oriented such that left - posterior, right - anterior, top - dorsal and bottom - ventral. $(\mathbf{I}, \mathbf{J}, \mathbf{Q})$ longitudinal limb sections are positioned such that left - proximal and right-distal. Embryonic stages of the limbs are mentioned in the upper right corner of the pictures. 
shown). Moreover, longitudinal sections revealed stronger expression in the perichondrium compared to the mesenchymal tissue (data not shown). At HH27, FgfR1 expression decreases prominently in the distal limb mesenchyme and becomes restricted to more proximal regions (Fig. 1K, arrow). In situ hybridisation of stage $\mathrm{HH} 31$ or $\mathrm{HH} 32$ forelimbs show that FgfR 1 is observed in the perichondrium and in the prospective interphalangic joints (Fig. $1 \mathrm{~N}-\mathrm{Q}$, arrowheads and $1 \mathrm{Q}$, arrow, respectively). In addition, FgfR1 expression is also observed in muscles (Fig. $1 \mathrm{~N}, \mathrm{~m}$ ), tendons (Fig. $1 \mathrm{~N}$ ) and in feather buds of the body wall (Fig. 1 L,M arrows). Interestingly, FgfR1 is strongly expressed in a thin layer of mesenchymal cells juxtaposed the limb ectoderm, with a higher signal in the dorsal regions (Fig. $1 \mathrm{~N}-\mathrm{Q}$ and $1 \mathrm{Q}$, inset) which fades gradually towards the distal limb.

\section{FgfR2 expression}

FgfR2 transcripts are strongly detected in the entire ectodermal cell layer covering limb mesenchymal cells, including the AER (Fig. 2). This is clearly evidenced in the transverse and longitudinal limb sections (Fig. 2 F$\mathrm{J}$, arrowhead). Additionally, FgfR2 transcripts can be observed in the proximal regions of stage $\mathrm{HH} 23-26$ limbs, including the anterior and posterior limb margins (Fig. 2 D,E,G,J, arrow). From stage HH27 onwards, FgfR2 mRNA is observed in between the two zeugopod skeletal elements and in the interdigital domains (Fig. 2 $\mathrm{K}, \mathrm{L}, \mathrm{M}$ arrow) and surrounding feather buds of the body wall (Fig. 2M, arrowhead). Section analyses showed that FgfR2 expression prefigures the distal developing chondrogenic elements (Fig. 2 P,Q, arrow), and was observed in the perichondrium of the more proximal cartilage elements (Fig. 2 N,O,Q, arrowhead).

Fig. 3. FgfR3 expression pattern during chick forelimb development. Chick wings at HH17-33 stages were processed for in situ hybridisation in whole-mounts (A-E, K-M) and transverse/longitudinal sections (F-J, N-Q) using a probe for non isoform specific chick FgfR3. (A-E) In situ hybridisation in whole mount limbs at stages HH19-24 show FgfR3 expression in the more proximal part of limb buds (B-D, arrows) and in forming cartilage elements (E) of the humerus ( $h$ ), radius ( $r$ ) and ulna (u) at HH25/26 stages. Faint FgfR3 expression was also observed in the anterior mesenchyme underlying the ectoderm ( $D$, arrowhead). (F-H) Transverse (G:proximal, $H$ :distal, represented in D as a and b, respectively) and $(\mathbf{I}, \mathbf{J})$ longitudinal limb sections at stage $\mathrm{HH} 19$ and $\mathrm{HH} 24$ shows the specific mesenchymal expression of FgfR3 (arrows). (K-M) In situ hybridisation in whole-mount limbs at $\mathrm{HH} 27$ to $\mathrm{HH} 33$ shows a FgfR3 expression in interdigital domains (arrows), in addition to digit cartilage elements (d2, $d 3$ and d4). FgfR3 expression is also observed around the feather buds in the body wall (arrowhead). (N-O) During limb stages HH31/32 FgfR3 is expressed in the ectoderm (asterisk \& inset) and also in the cartilage elements (arrows) and perichondrium (arrowhead). (A-E, K-M) are dorsal views of whole-mount limbs. (F$\mathbf{H}, \mathbf{N}-\mathbf{P})$ transverse sections are oriented such that left posterior, right - anterior, top - dorsal and bottom - ventral. $(\mathbf{I}, \mathbf{J}, \mathbf{Q})$ longitudinal limb sections are positioned such that left - proximal and right-distal. Embryonic stages of the limbs are mentioned in the upper right corner of the pictures.

\section{FgfR3 expression}

FgfR3 transcripts were first detected in limb buds at stage $\mathrm{HH} 19$, where they are clearly restricted to the most proximal mesoderm (Fig. $3 \mathrm{~B}-\mathrm{J}$, arrow). This expression pattern is maintained until stage HH24. However, low levels of FgfR3 expression in the mesenchyme underlying the anterior ectoderm towards the distal part of the limb could also be observed (Fig. 3D, arrowhead). FgfR3 mRNA was never detected neither in the ZPA nor in the AER and the underlying distal mesenchyme (Fig. 3 A-J), although it could be detected in the proximal mesoderm (Fig. 3J, arrow). From HH25 stage, FgfR3 is strongly expressed in all the
A
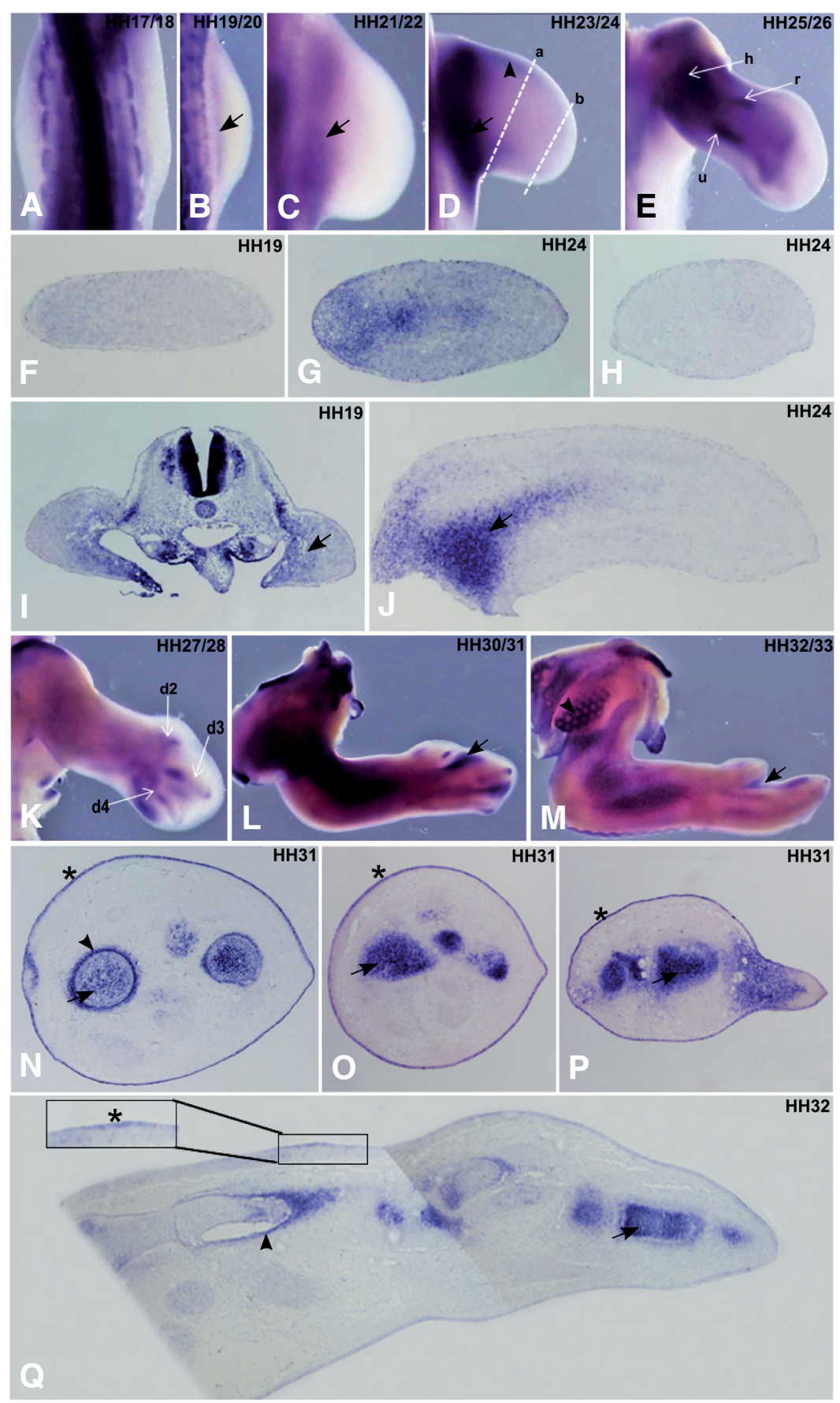


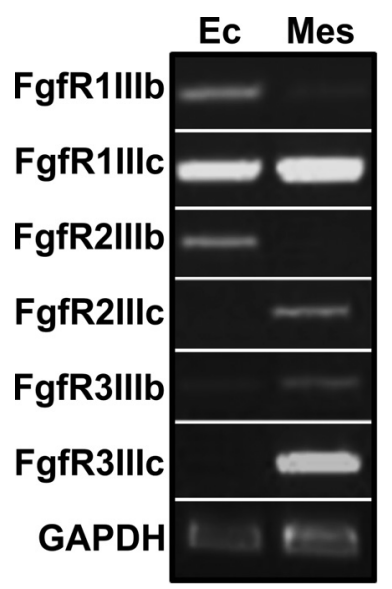

Fig. 4. RT-PCR evaluation of the differential expression of FgfR1-3 IIlb and Illc isoforms in the forelimb ectoderm and mesoderm. FgfR1-3 isoform-specific expression was evaluated by $R T$ $P C R$ using total RNA extracted from segregated ectoderm $(E C)$ and mesoderm (Mes) tissues from stage $\mathrm{HH} 24$ forelimbs. FgfR1IIlb, FgfR1 IIIc and FgfR3IIlb are found in both ectoderm and mesenchyme. FgfR2IIlb is exclusively expressed in the ectoderm, while FgfR2IIlc and FgfR3IIIc are only expressed in the mesenchyme.

forming cartilage elements (Fig. $3 \mathrm{E}, \mathrm{K}$ ) and can also be observed in interdigital zones (Fig. 3 L,M, arrow). Sections of $\mathrm{HH} 32$ limbs revealed specific expression of FgfR3 in muscles (Fig. $3 \mathrm{~N}$ ), distal cartilage elements (Fig. $3 \mathrm{~N}-\mathrm{Q}$, arrow) and in the perichondrium (Fig. $3 \mathrm{~N}, \mathrm{Q}$, arrowhead). Interestingly, FgfR3 is also faintly expressed in the ectoderm at this stage of limb development (Fig. $3 \mathrm{~N}-\mathrm{Q}$, asterisk and inset).

\section{Isoform-specific expression patterns of FgfRs 1-3}

We employed the same experimental approach as Shin et al. (2005) to detect the presence of the specific IIIb and IIIC isoforms of FgfR1-3 in segregated ectoderm and mesoderm tissues of stage $\mathrm{HH} 24$ limb buds. RT-PCR analysis clearly revealed that FgfR2IIIb is exclusively expressed in the limb ectoderm, while FgfR2IIIc and FgfR3IIIC are only found in limb mesenchyme (Fig. 4). These results strongly imply that the FgfR2 ectodermal staining observed in Fig. 2 is due to FgfR2IIlb isoform expression. Conversely, FgfR2 mesodermal staining is a result of FgfR2IIIC expression. Since FgfR3IIIC can only be detected in the limb mesoderm by RTPCR (Fig. 4), we can clearly state that at stage $\mathrm{HH} 24$ the faint FgfR3 ectodermal staining observed by in situ hybridization (Fig. 3G) is solely due to the FgfR3IIIb isoform expression. However, RT-PCR also detected this splice variant

Fig. 5. Section in situ hybridization analyses of FgfR1IIIb, FgfR1IIIc, FgfR3IIIb and FgfR3IIIc expression patterns. Chick wings at $\mathrm{HH} 24$ and $\mathrm{HH} 30 / 31$ stages were processed for transversal/longitudinal paraffin section in situ hybridisation using the isoform-specific sequences previously obtained as probes (GenBank accession numbers GU053725, GU065444, GU053726, GU065445). FgfR1Illb presents stronger expression in the ectoderm than FgfR1II/c; see arrows in (A-D), while FgfR1IIlc transcripts could be detected in the perichondrium; see arrowhead in (D) unlike FgfR1/llb. FgfR3/llc is expressed in the proximal limb of stage $\mathrm{HH} 24$; see arrow in (G), and in the cartilage elements at stage HH30; arrow in (H), unlike FgfR3/Ilb (E, F). Atstage HH30, both FgfR3IIIb and IIIC are expressed in the ectoderm; see asterisks in $(\mathbf{F}, \mathrm{H})$. in the mesenchyme (Fig. 4), so detailed FgfR3 isoform-specific expression patterns in the limb mesenchyme are missing. The same stands for FgfR1 isoforms, since both are detected by RTPCR in ectoderm and mesoderm (Fig. 4).

To further elucidate the expression patterns of FgfR1 and FgfR3 isoforms, in situ hybridization probes were prepared using the amplification products obtained upon RT-PCR performed on total RNA extracted from $\mathrm{HH} 24$ whole chick embryos, using the primers previously described (Shin et al. 2005). The amplicon sequences were determined and deposited in GenBank with the following accession numbers: FgfR1/l/bGU053725; FgfR1/IIc- GU065444; FgfR3IIIb- GU053726; FgfR3IIIC-GU065445.

In situ hybridization of FgfR1/llb and FgfR1/llc isoforms on limb sections (Fig. 5) consistently showed fainter staining compared to the non isoform-specific' FgfR1 probe. Very subtle differences could be found for the spatial distribution of both isoforms in the limb tissues: FgfR $1 / I / b$ consistently marked the ectoderm stronger than the FgfR 1Illc isoform (Fig. 5 A,B,C,D, arrows) and, in stage $\mathrm{HH} 31$ limb sections, FgfR1IIIc presents stronger expression in the perichondrium than the other variant (Fig. 5 B,D, arrowhead).

At stage $\mathrm{HH} 24$, FgfR3IIlb is expressed throughout the entire limb and the FgfR3IIlC isoform is expressed in the proximal mesenchyme (Fig. 5 E,G, arrow), which is in accordance to the RT-PCR results (Fig. 4). In later developmental stages (HH30), FgfR3IIIc transcripts are predominantly detected in and around the cartilage, unlike the faint expression of FgfR3IIlb (Fig. 5

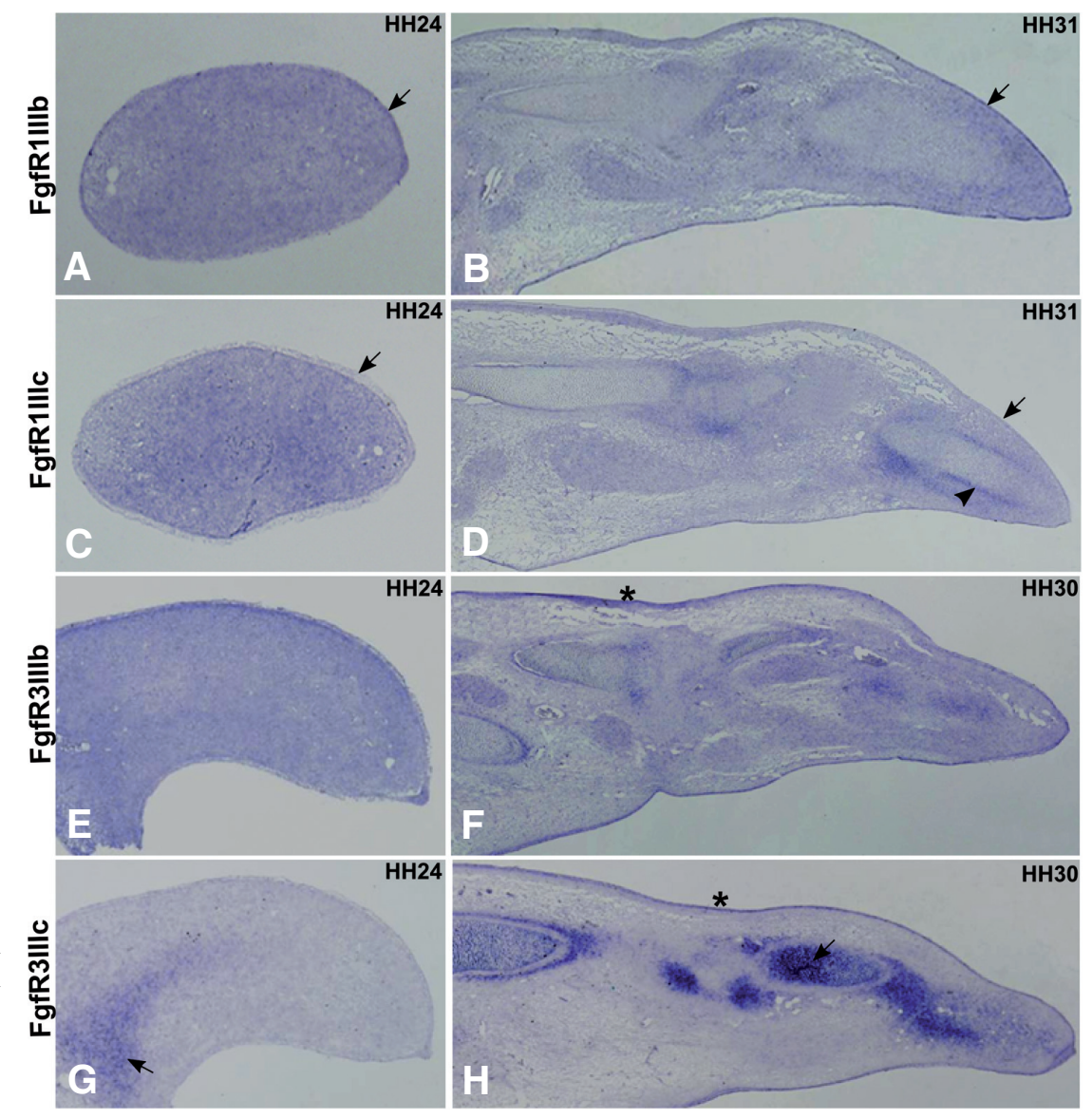




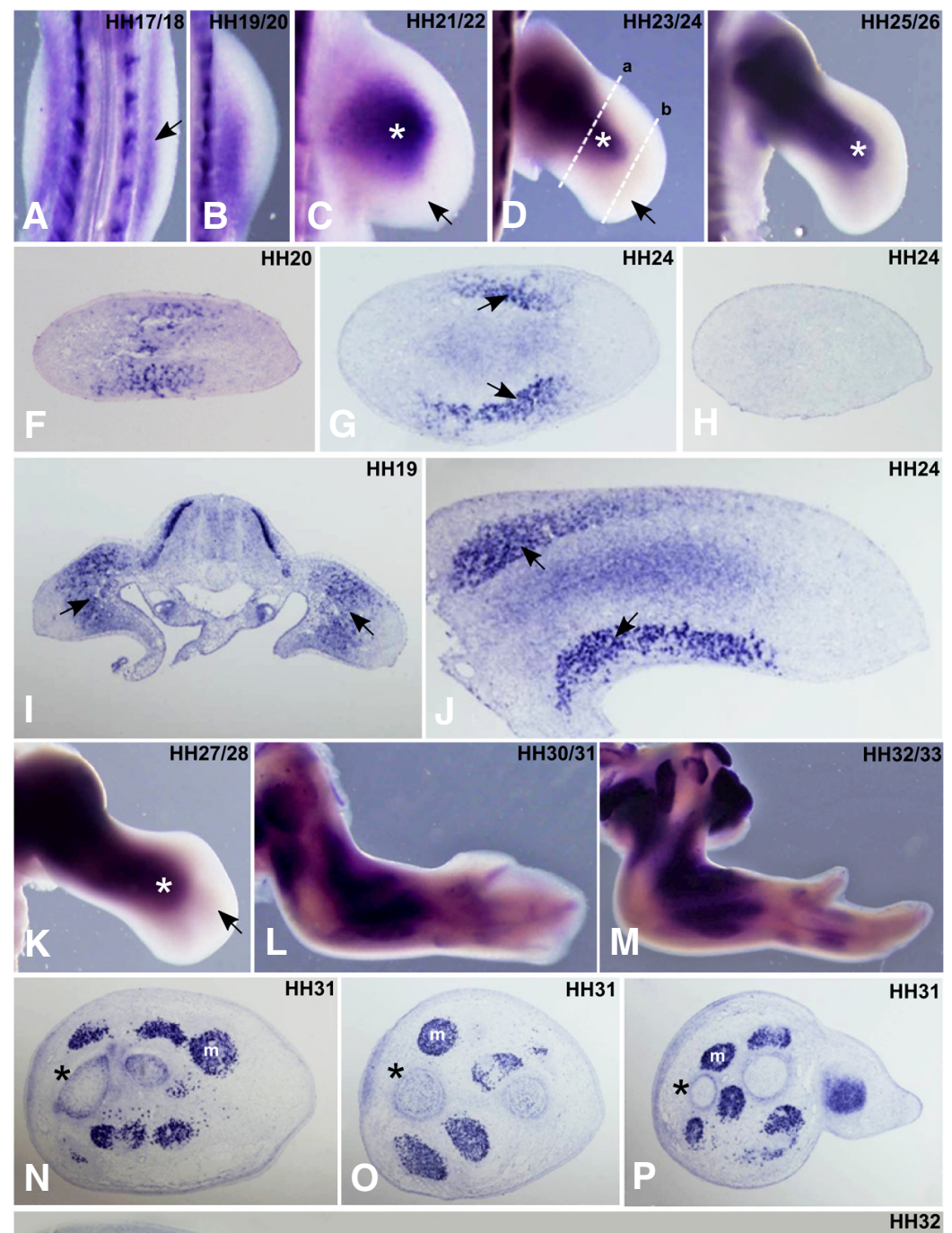

HH32

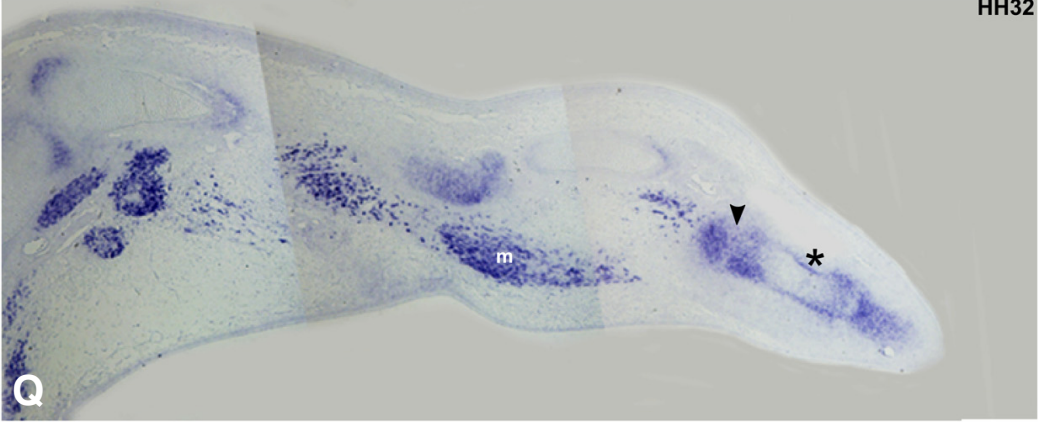

Fig. 6. FgfR4 expression pattern during chick forelimb development. Chick wings at HH17-33 stages were processed for in situ hybridisation in whole-mounts (A-E, K-M) and transverse/longitudinal sections (F-J, N-Q) using a probe for non isoform specific chick FgfR4. (A-E) In situ hybridisation in whole-mount limbs shows limb FgfR4 expression at HH17 (A, arrow). There is no FgfR4 expression in the AER and ZPA (C,D, arrows), while FgfR4 expression is observed in muscle masses (asterisks; also in K). (F-H) Transverse sections of $\mathrm{HH} 2 \mathrm{O}$ and HH24 limbs (G: proximal, H: distal, represented in (D) as (a) and (b), respectively) reveal FgfR4 expression in the dorsal and ventral muscle masses (G, arrows). (I,J) Longitudinal sections of HH19 and HH24 limbs indicate FgfR4 expression in muscle precursors (I, arrows) and then in dorsal and ventral muscle masses (J, arrows). (K-M) In situ hybridisation experiments in whole mount limbs at $\mathrm{HH} 27$ to HH33 show an absence of FgfR4 expression in distal limb mesenchyme (K, arrow). In limb stage HH31 FgfR3 is expressed in the perichondrium ( $N-P$, asterisk) and in the muscle tissue (N-P, m). (Q) In situ hybridisation in longitudinal limb sections at HH32 shows FgfR4 expression in individualised muscles $(\mathrm{m})$, in the perichondrium of distal cartilage elements (asterisk) and interphalangic joints (arrowhead). (A-E, K-M) are dorsal views of whole-mount limbs. (F$\mathbf{H}, \mathbf{N}-\mathbf{P})$ Transverse sections are oriented such that left, posterior; right, anterior; top, dorsal; bottom, ventral. (I,J, Q) longitudinal limb sections are positioned such that left is proximal and right is distal. Embryonic stages of the limbs are mentioned in the upper right corner of the pictures.

al. 1995). There is no FgfR4 expression in the AER, the underlying distal mesenchyme and in the ZPA (Fig. 6 $\mathrm{C}-\mathrm{E})$. From stage $\mathrm{HH} 29$ on, FgfR4 expression is also located in limb cartilage element domains (Fig. 6 L-Q), as previously described (Marcelle et al. 1995). Analysis of longitudinal and cross sections at stage $\mathrm{HH} 31 / 32$ revealed that this gene is weakly expressed in the perichondrium and interphalangic joints (Fig. $6 \mathrm{~N}-\mathrm{Q}$ asterisk and arrowhead, respectively), in addition to its stronger expression in individualised muscles (Fig. 6 $\mathrm{N}-\mathrm{Q}, \mathrm{m})$.

\section{Discussion}

Fgf signalling plays an important role in many aspects of limb development, such as initiation, outgrowth and patterning (reviewed in Martin, 1998; Xu et al. 1999; Yu and Ornitz, 2008). In this study we performed a careful examination of the spatio-temporal expression patterns of FgfR1-4 genes and IIIb and IIIC

$\mathrm{F}, \mathrm{H}$, arrow). Moreover, both isoforms can be observed in the ectoderm at this stage (Fig. $5 \mathrm{~F}, \mathrm{H}$, asterisk).

\section{FgfR4 expression}

Analysis of FgfR4 expression patterns showed that this receptor starts being expressed in the most proximal part of limb buds at stage $\mathrm{HH} 17$ (Fig. 6A, arrow). From stage HH21 to HH28 FgfR4 is persistently expressed in a central mesenchymal domain, which extends distally as the limb develops (Fig. 6 C-E,K asterisk). Transverse and longitudinal section in situ hybridization analyses showed that this expression is most predominant in the dorsal and ventral muscle masses (Fig. $6 \mathrm{G}, \mathrm{J}$ arrow, Marcelle et isoforms of FgfR1-3 during chick wing development.

\section{FgfR expression in the AER and in the underlying undifferen- tiated mesenchyme}

The AER constitutes the signalling centre responsible for limb outgrowth along the PD axis. Fgfs produced by the AER signal to the underlying mesenchyme or to the neighbouring ectoderm, which express Fgf receptors and various components of the Fgf signalling pathway. Our results show that during early limb patterning events (HH17-20), FGFR1 and FGFR2 are expressed in the developing chick forelimb buds. FgfR1 is the main Fgf receptor to be expressed in the undifferentiated mesenchymal cells 
located in the distal part of the limb. FgfR2 expression is also detected in the mesenchyme but not in the distal limb region. Interestingly, the distal expression of FgfR 1 is progressively lost at stages $\mathrm{HH} 26-28$, which correspond to the stages when distal autopod skeletal elements are being laid down. FgfR1 involvement in growth and patterning of vertebrate limbs was first evidenced by the targeted mutation of FgfR1, which affected autopod patterning in mice (Partanen et al. 1998). More recently, conditional deletion of FgfR1 gene in mouse embryos suggested a three phase function for FgfR1: elongation of PD axis at early stages, mesenchymal cell survival at middle stages and patterning autopod at later stages (Verheyden et al. 2005). Supporting its role in later stages, previous studies show that mutant mouse embryos carrying a targeted deletion of the $F g f R 1 \alpha(I / l c)$ isoform exhibited distal truncation of limb buds which were shorter in PD axis and wider in AP axis (reviewed in Xu et al. 1999).

Our whole-mount analyses show that FgfR2 is the only FgfR to be robustly expressed in the entire ectoderm, including the AER, throughout all stages of development. This expression pattern supports the idea that chick FgfR2 is mediating the Fgf signal in AER formation, ectodermal cell movements towards and into the limb as well as in certain aspects of dorsoventral ectodermal polarity establishment, as already described in mice (Gorivodsky and Lonai, 2003). FgfR2 expressed in the AER has been reported to be essential for the maintenance of this structure (Lu et al. 2008). These authors also reported the loss of autopod in mouse forelimb upon conditional removal of FgfR2from the AER bringing forth the involvement of FgfR2 in distal limb patterning. Among the two FgfR2 isoforms, FgfR2IIlb variant is implicated in mesenchymal-epithelial signalling loop in limb bud initiation (De Moerlooze et al. 2000), whereas the FgfR2IIlc form is associated to limb skeletal bone formation (Eswarakumar et al. 2002). Recently, conditional inactivation of mouse FgfR2 from the AER and both FgfR1 and FgfR2 from the mesenchyme suggest that AER-Fgfs function not only as survival factors but also as regulators of mesenchymal proliferation and chondrogenic differentiation ( $\mathrm{Yu}$ and Ornitz, 2008). Overall, FgfR1 and FgfR2 are involved in limb initiation and patterning.

FgfR3 and FgfR4 are not expressed in the AER or in the underlying undifferentiated zone throughout all chick limb developmental stages.

\section{Fgf signaling in the ZPA}

The ZPA is another important limb signalling centre, which produces Shh and organizes the limb along the AP axis. It has been shown that there is a positive feed-back loop between Shh expressed in the ZPA and Fgf4 expressed in the AER, which is important for limb development (reviewed in Towers and Tickle, 2009). Our whole-mount in situ hybridisation analyses show that FgfR1 is the unique FgfR continuously expressed in the ZPA from stage $\mathrm{HH} 17$ to 26 , suggesting that FgfR1 is involved in this regulatory loop. Accordingly, conditional inactivation of FgfR1 in posterior limb caused reduction in Shh RNA levels and consequently affected digit identity (Verheyden et al. 2005).

\section{FgfRs and cartilage development}

Our whole-mount and section analyses showed that all four FgfRs are expressed during chondrogenesis in the chick wing. FgfR1 is strongly expressed in perichondrium and in forming joints. FgfR1 expression in cartilage elements displays no variation along the PD axis of the limb. In contrast, FgfR2, 3 and 4 expression in cartilage elements varies along the PD axis, being expressed in the more distal cartilage elements and becoming restricted to the perichondrium as development proceeds. Mutations in FgfR1, 2 or 3 genes lead to human limb congenital disorders (Wilkie et al. 2002; Coumoul and Deng, 2003). In addition FgfR1 and FgfR3 have been described to take part in bone fracture repair (Nakajima et al. 2001; Nakajima et al. 2003). The involvement of FgfR3 in chondrogenesis and its mutation in inherited defective growth of human long bones syndrome was reported earlier (Colvin et al. 1996; Deng et al. 1996; Delezoide et al. 1998). Recently, the involvement of Fgf signalling through FgfR3 in the commitment of pre-chondrogenic mesenchymal cells to chondrogenesis and to cartilage production was documented (Davidson et al. 2005). Activating FgfR3 in mice can mimic human dwarfism (Li et al. 1999) and lack of FgfR3 causes skeletal overgrowth (Colvin et al. 1996; Deng et al. 1996), indicating that FgfR3 acts as a negative regulator of bone development. The downstream pathways responsible for the negative regulation are the MAP kinase pathway that inhibits chondrocyte differentiation and the Stat1 pathway that inhibits chondrocyte proliferation (Murakami et al. 2004).

Our observation of FgfR2 expression surrounding cartilage elements during limb development is in agreement with the suggestion that FgfR2 activation elicits a lateral inhibition of chondrogenesis that limits the expansion of developing skeletal elements (Moftah et al. 2002). Finally, although mouse homozygous for targeted FgfR4 mutation was normal, double homozygous disruption for both FgfR3 and 4 showed defects in long bone growth indicating that FgfR4 could also be a positive regulator of long bone growth (Weinstein et al. 1998; Lazarus et al. 2007).

\section{FgfRs and muscle formation}

Precursors of limb muscles orginate from the somites, migrate to the limb and undergo differentiation. In all chick limb bud stages analysed, FgfR4 expression is observed in migrating myogenic cells, in dorsal and ventral muscle masses and then in individualised muscles, consistent with its involvement in limb myogenesis (Marcelle et al. 1995; Marics et al. 2002). FgfR4 signalling has been shown to participate in terminal skeletal muscle differentiation in the embryo and during muscle regeneration process in the adult (Marics et al. 2002; Yu et al. 2004; Zhao et al. 2006). However, FgfR4 is not the only FgfR expressed in muscles but also FgfR1 expression is observed (Fig. $1 \mathrm{~N}$ ), as previously described (Edom-Vovard et al. 2001a, b, Eloy-Trinquet et al. 2009). Interestingly, down-regulation of FgfR1 signalling has also been correlated with terminal myogenic differentiation (Grothe et al. 1996; Itoh et al. 1996). So, two FgfRs are associated with muscle formation, FgfR1 and 4. However, their precise role in limb myogenesis is still unclear.

\section{FgfRs and feather development}

We would also like to point out the expression of FgfRs in the context of feather development. Our findings that all FgfRs except FgfR4 are expressed either in (FgfR1) or around (FgfR2 and 3) presumptive feather buds correlates with previously reported data (Noji et al. 1993). Recently the importance of FgfR1 and FgfR2 in feather development was demonstrated using dominant 
negative forms (Mandler and Neubuser, 2004).

\section{Conclusions}

The results obtained throughout our work are overall in accordance to what has been previously described (Szebenyi et al. 1995). We additionally report FgfR1 expression in the distal ectoderm, including the AER and FgfR3 in the ectoderm of late limb developmental stages (HH31). The expression patterns of the different FgfRs are consistent with their involvement in different steps of limb development, such as early limb bud formation, outgrowth and patterning. FgfR expression is also linked with the differentiation process of various cell types including, cartilage, muscle and feathers. Finally, we have analysed, for the first time, the expression of the different isoforms of FgfR1 and FgfR3 (FgfR1IIIb, FgfR1IIlc, FgfR3IIlb and $F g f R 3 / I C$ ). The results obtained highlight the importance of the epithelial-mesenchymal tissue interactions operating during limb development. The relative affinity of each FgfR isoform to the different limb Fgfs has been previously described (Ornitz et al. 1996; Zhang et al. 2006), and our FgfR expression profiles evidence a trend in that the ectodermal-expressed isoforms, such as FgfR2IIIb, respond to mesenchyme-produced Fgfs (Fgf10), while FgfR isoforms found in the mesoderm preferentially react to ectodermal-derived Fgfs. This is particularly evident for FgfR2IIIc and FgfR3IIIc which recognize Fgf2,4,8,9 and Fgf2,8,9, respectively.

\section{Materials and Methods}

\section{Eggs and embryos}

Fertilised chick (Gallus gallus) eggs obtained from commercial sources were incubated at $38^{\circ} \mathrm{C}$ in a $49 \%$ humidified atmosphere and staged according to the Hamburger and Hamilton $(\mathrm{HH})$ classification (Hamburger and Hamilton, 1951).

\section{In situ hybridisation probes}

Non isoform-specific chick FgfR1-4 probes were kindly provided by Dr. Guojun Sheng (Nakazawa et al. 2006). In situ hybridisation probes for FgfR 1-3 IIIb and IIlc isoforms were generated by amplifying portions of these genes by reverse transcription and polymerase chain reactions (RT-PCR) using the isoform-specific primers previously described in Sinh et al. (2005). The DNA fragments generated were cloned into the pCR®II-TOPO® vector (Invitrogen, USA) and plasmid DNA was isolated. The constructs were confirmed upon sequencing. Digoxigenin-labelled RNA probes were synthesized using linearised plasmids, according to standard procedures.

\section{In situ hybridisation of whole-mount embryos and tissue sections}

Embryos were fixed overnight at $4{ }^{\circ} \mathrm{C}$ in a solution of $4 \%$ formaldehyde with $2 \mathrm{mM}$ EGTA in PBS at pH 7.5, rinsed in PBT (PBS, $0.1 \%$ Tween 20), dehydrated in methanol and stored at $-20^{\circ} \mathrm{C}$. Whole mount in situ hybridisation was performed as previously described (Henrique et al. 1995).

Paraffin sections were prepared as follows: stage $\mathrm{HH} 32$ chick wings were collected in PBS and fixed at $4^{\circ} \mathrm{C}$ over night in a solution of $60 \%$ ethanol, $30 \%$ formaldehyde and $10 \%$ acetic acid. The following day, limbs were dehydrated in series of ethanol with a final step of xylene. Finally, they were incubated in paraffin at $70^{\circ} \mathrm{C}$ for $30 \mathrm{~min}$, placed in the desired orientation and left to solidify. Longitudinal limb sections of 10 $\mu \mathrm{m}$ were made using Microm HM325 on SuperFrost Plus (MenzelGlaser) slides and allowed to dry at $37^{\circ} \mathrm{C}$ overnight. In situ hybridisation on paraffin sections was performed as described previously (Tozer et al. 2007).

\section{RNA extraction from limb tissues and RT-PCR reactions}

Stage $\mathrm{HH} 24$ chick fore-limbs were submitted to pancretin-mediated digestion until the ectoderm detached freely from the mesoderm. The reaction was stopped by the addition of goat serum solution (Invitrogen). The ectoderm was isolated from the mesoderm and both tissues were collected separately for RNA isolation using the RNeasy Mini Kit Protect (Qiagen, Germany). Total mRNA quantification was done by spectrophotometry (NanoDrop Technologies, Inc., USA). Total RNA was digested with DNAse RNAse-Free (Promega, USA) according to manufacturer's instructions. Purified RNA was reverse transcribed using SuperScript ${ }^{\mathrm{TM}}$ II Reverse Transcriptase (Invitrogen), and a PCR reaction was performed employing the FgfR isoform-specific primer pairs described by Shin et al. (2005).

\section{Imaging}

Embryos processed for in situ hybridisation were photographed in $\mathrm{PBT} / 0.1 \%$ azide, using an Olympus DP71 digital camera coupled to an Olympus SZX16 stereomicroscope equipped with Cell^B program. Vibratome and paraffin limb sections were photographed using an Olympus DP70 camera coupled to an Olympus BX61 microscope.

\section{Acknowledgements}

The authors wish to thank Anja Hagemann for critical reading of the manuscript and Ramiro Magno, , Fernanda Bajanca and Tatiana Resende for their help with the figures. We thank Dr. Guojun Sheng for the gift of the FgfR1-4 probes. We also acknowledge Tatiana Queirós for contributing to the initiation of this project. CJS is supported by Fundação para a Ciência e Tecnologia (grant n ${ }^{\circ}$ SFRH/BD/33176/2007) and RPA is funded by a Ciência2007 Program Contract (Portuguese Government). This work was supported by the Fundação para a Ciência e Tecnologia, Portugal (project PTDC/SAU-OBD/099758/2008), and by EU/FP6 - Network of Excellence - Cells into Organs (www.cellsintoorgans.net) and by "IBB/CBME, LA, FEDER/POCI 2010".

\section{References}

BOTTCHER, R.T. and NIEHRS, C. (2005). Fibroblast growth factor signaling during early vertebrate development. Endocr Rev 26: 63-77.

BOULET, A.P., MOON, A.M., ARENKIEL, B.R. and CAPECCHI, M.R. (2004). The roles of Fgf4 and Fgf8 in limb bud initiation and outgrowth. Dev Biol 273: 361 372.

BUCKINGHAM, M., BAJARD, L., CHANG, T., DAUBAS, P., HADCHOUEL, J. MEILHAC, S., MONTARRAS, D., ROCANCOURT, D. and RELAIX, F. (2003). The formation of skeletal muscle: from somite to limb. J Anat 202: 59-68.

CHEN, H., LUN, Y., OVCHINNIKOV, D., KOKUBO, H., OBERG, K.C., PEPICELLI, C.V., GAN, L., LEE, B. and JOHNSON, R.L. (1998). Limb and kidney defects in Lmx1b mutant mice suggest an involvement of LMX1B in human nail patella syndrome. Nat Genet 19: 51-55.

CHRIST, B. and BRAND-SABERI, B. (2002). Limb muscle development. Int J Dev Biol 46: 905-914.

COLVIN, J.S., BOHNE, B.A., HARDING, G.W., MCEWEN, D.G. and ORNITZ, D.M (1996). Skeletal overgrowth and deafness in mice lacking fibroblast growth factor receptor 3. Nat Genet 12: 390-397.

COUMOUL, X. and DENG, C.X. (2003). Roles of FGF receptors in mammalian development and congenital diseases. Birth Defects Res C Embryo Today 69: 286-304.

CROSSlEY, P.H., MINOWADA, G., MACARTHUR, C.A. and MARTIN, G.R (1996). Roles for FGF8 in the induction, initiation, and maintenance of chick limb development. Cell 84: 127-136.

DAILEY, L., AMBROSETTI, D., MANSUKHANI, A. and BASILICO, C. (2005) Mechanisms underlying differential responses to FGF signaling. Cytokine Growth Factor Rev 16: 233-247.

DAVIDSON, D., BLANC, A., FILION, D., WANG, H., PLUT, P., PFEFFER, G., BUSCHMANN, M.D. and HENDERSON, J.E. (2005). Fibroblast growth factor (FGF) 18 signals through FGF receptor 3 to promote chondrogenesis. $J$ Biol 
Chem 280: 20509-20515.

DELEZOIDE, A.L., BENOIST-LASSELIN, C., LEGEAI-MALLET, L., LE MERRER, M., MUNNICH, A., VEKEMANS, M. and BONAVENTURE, J. (1998). Spatiotemporal expression of FGFR 1, 2 and 3 genes during human embryo-fetal ossification. Mech Dev 77: 19-30.

DE MOERLOOZE, L., SPENCER-DENE, B., REVEST, J., HAJIHOSSEINI, M., ROSEWELL, I. and DICKSON, C. (2000). An important role for the IIlb isoform of fibroblast growth factor receptor 2 (FGFR2) in mesenchymal-epithelial signalling during mouse organogenesis. Development 127: 483-492.

DENG, C., WYNSHAW-BORIS, A., ZHOU, F., KUO, A. and LEDER, P. (1996). Fibroblast growth factor receptor 3 is a negative regulator of bone growth. Cell 84: 911-921.

DUPREZ, D. (2002). Signals regulating muscle formation in the limb during embryonic development. Int J Dev Biol 46: 915-925.

EDOM-VOVARD, F., BONNIN, M.A. and DUPREZ, D. (2001a). Misexpression of Fgf-4 in the chick limb inhibits myogenesis by down-regulating Frek expression. Dev Biol 233: 56-71.

EDOM-VOVARD, F., BONNIN, M.A and DUPREZ, D. (2001b). Fgf8 transcripts are located in tendons during embryonic chick limb development. Mech Dev 108: 203-206.

ELOY-TRINQUET, S., WANG, H., EDOM-VOVARD, F. and DUPREZ, D. (2009). Fgf Signaling Components Are Associated With Muscles and Tendons During Limb Development. Dev Dyn 238: 1195-1206.

ESWARAKUMAR, V.P., LAX, I. and SCHLESSINGER, J. (2005). Cellular signaling by fibroblast growth factor receptors. Cytokine Growth Factor Rev 16: 139-149.

ESWARAKUMAR, V.P., MONSONEGO-ORNAN, E., PINES, M., ANTONOPOULOU, I., MORRISS-KAY, G.M. and LONAI, P. (2002). The IIIC alternative of Fgfr2 is a positive regulator of bone formation. Development 129: 3783-3793.

FALLON, J.F., LOPEZ, A., ROS, M.A., SAVAGE, M.P., OLWIN, B.B. and SIMANDL, B.K. (1994). FGF-2: apical ectodermal ridge growth signal for chick limb development. Science 264: 104-107.

GORIVODSKY, M. and LONAI, P. (2003). Novel roles of Fgfr2 in AER differentiation and positioning of the dorsoventral limb interface. Development 130: 54715479.

GROTHE, C., BRAND-SABERI, B., WILTING, J. and CHRIST, B. (1996). Fibroblast growth factor receptor 1 in skeletal and heart muscle cells: expression during early avian development and regulation after notochord transplantation. Dev Dyn 206: 310-317.

HAMBURGER, V. and HAMILTON, H.L. (1951). A series of normal stages in the development of the chick embryo. J Morphol 88: 49-92.

HAVENS, B.A., RODGERS, B. and MINA, M. (2006). Tissue-specific expression of Fgfr2b and Fgfr2c isoforms, Fgf10 and Fgf9 in the developing chick mandible. Arch Oral Biol 51: 134-145.

HENRIQUE, D., ADAM, J., MYAT, A., CHITNIS, A., LEWIS, J. and ISH-HOROWICZ, D. (1995). Expression of a Delta homologue in prospective neurons in the chick. Nature 375: 787-790.

ITOH, N., MIMA, T. and MIKAWA, T. (1996). Loss of fibroblast growth factor receptors is necessary for terminal differentiation of embryonic limb muscle. Development 122: 291-300.

LAZARUS, J.E., HEGDE, A., ANDRADE, A.C., NILSSON, O. and BARON, J. (2007). Fibroblast growth factor expression in the postnatal growth plate. Bone 40: 577-586.

LI, C., CHEN, L., IWATA, T., KITAGAWA, M., FU, X.Y. and DENG, C.X. (1999). A Lys644Glu substitution in fibroblast growth factor receptor 3 (FGFR3) causes dwarfism in mice by activation of STATs and ink4 cell cycle inhibitors. Hum Mol Genet 8: 35-44.

LIZARRAGA, G., FERRARI, D., KALINOESKI, M., OHUCHI, H., NOJI, S., KOSHER, R. A. and DEALY, C. N. (1999). FGFR2 signaling in normal and limbless chick limb buds. Dev Genet 25 (4): 331-338.

LOOMIS, C.A., HARRIS, E., MICHAUD, J., WURST, W., HANKS, M. and JOYNER, A.L. (1996). The mouse Engrailed-1 gene and ventral limb patterning. Nature 382: 360-363.

LU, P., YU, Y., PERDUE, Y. and WERB, Z. (2008). The apical ectodermal ridge is a timer for generating distal limb progenitors. Development 135: 1395-1405.
MANDLER, M. and NEUBUSER, A. (2004). FGF signaling is required for initiation of feather placode development. Development 131: 3333-3343.

MARCELLE, C., WOLF, J. and BRONNER-FRASER, M. (1995). The in vivo expression of the FGF receptor FREK $m$ RNA in avian myoblasts suggests a role in muscle growth and differentiation. Dev Biol 172: 100-114.

MARIANI, F.V., AHN, C.P. and MARTIN, G.R. (2008). Genetic evidence that FGFs have an instructive role in limb proximal-distal patterning. Nature 453: 401-405.

MARICS, I., PADILLA, F., GUILLEMOT, J.F., SCAAL, M. and MARCELLE, C. (2002). FGFR4 signaling is a necessary step in limb muscle differentiation. Development 129: 4559-4569.

MARTIN, G.R. (1998). The roles of FGFs in the early development of vertebrate limbs. Genes Dev 12: 1571-1586.

MOFTAH, M.Z., DOWNIE, S.A., BRONSTEIN, N.B., MEZENTSEVA, N., PU, J., MAHER, P.A. and NEWMAN, S.A. (2002). Ectodermal FGFs induce perinodular inhibition of limb chondrogenesis in vitro and in vivo via FGF receptor 2. Dev Biol 249: $270-282$

MUNOZ-SANJUAN, I., SIMANDL, B.K., FALLON, J.F. and NATHANS, J. (1999). Expression of chicken fibroblast growth factor homologous factor (FHF)-1 and of differentially spliced isoforms of FHF-2 during development and involvement of FHF-2 in chicken limb development. Development 126: 409-421.

MURAKAMI, S., BALMES, G., MCKINNEY, S., ZHANG, Z., GIVOL, D. and DE CROMBRUGGHE, B. (2004). Constitutive activation of MEK1 in chondrocytes causes Stat1-independent achondroplasia-like dwarfism and rescues the Fgfr3deficient mouse phenotype. Genes Dev 18: 290-305.

NAKAJIMA, A., NAKAJIMA, F., SHIMIZU, S., OGASAWARA, A., WANAKA, A., MORIYA, H., EINHORN, T.A. and YAMAZAKI, M. (2001). Spatial and temporal gene expression for fibroblast growth factor type I receptor (FGFR1) during fracture healing in the rat. Bone 29: 458-466.

NAKAJIMA, A., SHIMIZU, S., MORIYA, H. and YAMAZAKI, M. (2003). Expression of fibroblast growth factor receptor-3 (FGFR3), signal transducer and activator of transcription-1, and cyclin-dependent kinase inhibitor p21 during endochondral ossification: differential role of FGFR3 in skeletal development and fracture repair. Endocrinology 144: 4659-4668.

NAKAZAWA, F., NAGAI, H., SHIN, M. and SHENG, G. (2006). Negative regulation of primitive hematopoiesis by the FGF signaling pathway. Blood 108: 33353343.

NISWANDER, L., TICKLE, C., VOGEL, A., BOOTH, I. and MARTIN, G.R. (1993) FGF-4 replaces the apical ectodermal ridge and directs outgrowth and patterning of the limb. Cell 75: 579-587.

NOJI S, KOYAMA E, MYOKAI F, NOHNO T, OHUCHI H, NISHIKAWA K and S., T. (1993). Differential expression of three chick FGF receptor genes, FGFR1, FGFR2 and FGFR3, in limb and feather development. Prog Clin Biol Res. 383B: 645-654.

OHUCHI, H., KIMURA, S., WATAMOTO, M. and ITOH, N. (2000). Involvement of fibroblast growth factor (FGF)18-FGF8 signaling in specification of left-right asymmetry and brain and limb development of the chick embryo. Mech Dev 95: 55-66.

OHUCHI, H., NAKAGAWA, T., YAMAMOTO, A., ARAGA, A., OHATA, T., ISHIMARU, Y., YOSHIOKA, H., KUWANA, T., NOHNO, T., YAMASAKI, M. et al. (1997). The mesenchymal factor, FGF10, initiates and maintains the outgrowth of the chick limb bud through interaction with FGF8, an apical ectodermal factor. Development 124: 2235-2244.

ORNITZ, D.M., XU, J., COLVIN, J.S., MCEWEN, D.G., MACARTHUR, C.A., COULIERI, F. O., GAO, G. and GOLDFARB, M. (1996). Receptor Specificity of the Fibroblast Growth Factor Family. J Biol Chem 271: 15292-15297.

PARR, B.A. and MCMAHON, A.P. (1995). Dorsalizing signal Wnt-7a required for normal polarity of D-V and A-P axes of mouse limb. Nature 374: 350-353.

PARTANEN, J., SCHWARTZ, L. and ROSSANT, J. (1998). Opposite phenotypes of hypomorphic and $Y 766$ phosphorylation site mutations reveal a function for Fgfr1 in anteroposterior patterning of mouse embryos. Genes Dev 12: 23322344.

PASCOAL, S. and PALMEIRIM, I. (2007). Watch-ing out for chick limb development. Int Comp Biol 47: 382-389.

PASCOAL, S., CARVALHO, C.R., RODRIGUEZ-LEON, J., DELFINI, M.C., DUPREZ, D., THORSTEINSDOTTIR, S. and PALMEIRIM, I. (2007a). A molecular clock operates during chick autopod proximal-distal outgrowth. J Mol Biol 368: 303- 
309.

PASCOAL, S., ANDRADE, R.P., BAJANCA, F. and PALMEIRIM, I. (2007b). Progressive mRNA decay establishes an mkp3 expression gradient in the chick limb bud. Biochem Biophys Res Commun 352: 153-157.

PRYKHOZHIJ, S.V. and NEUMANN, C.J. (2008). Distinct roles of Shh and Fgf signaling in regulating cell proliferation during zebrafish pectoral fin development. BMC Dev Biol 8: 91.

SAUNDERS, J.W., JR. (1948). The proximo-distal sequence of origin of the parts of the chick wing and the role of the ectoderm. J Exp Zool 108: 363-403.

SAVAGE, M.P. and FALLON, J.F. (1995). FGF-2 mRNA and its antisense message are expressed in a developmentally specific manner in the chick limb bud and mesonephros. Dev Dyn 202: 343-353.

SHIN, M., WATANUKI, K. and YASUGI, S. (2005). Expression of Fgf10 and Fgf receptors during development of the embryonic chicken stomach. Gene Exp Patterns 5: 511-516.

SUN, X., MARIANI, F.V. and MARTIN, G.R. (2002). Functions of FGF signalling from the apical ectodermal ridge in limb development. Nature 418: 501-508.

SZEBENYI, G., SAVAGE, M.P., OLWIN, B.B. and FALLON, J.F. (1995). Changes in the expression of fibroblast growth factor receptors mark distinct stages of chondrogenesis in vitro and during chick limb skeletal patterning. Dev Dyn 204: 446-456.

TABIN, C. and WOLPERT, L. (2007). Rethinking the proximodistal axis of the vertebrate limb in the molecular era. Genes Dev 21: 1433-1442.

TODT, W.L. and FALLON, J.F. (1984). Development of the apical ectodermal ridge in the chick wing bud. J Embryol Exp Morphol 80: 21-41.

TOWERS, M. and TICKLE, C. (2009). Growing models of vertebrate limb development. Development 136: 179-190.

TOZER, S., BONNIN, M.A., RELAIX, F., DI SAVINO, S., GARCIA-VILLALBA, P.,
COUMAILLEAU, P. and DUPREZ, D. (2007). Involvement of vessels and PDGFB in muscle splitting during chick limb development. Development 134: 2579-2591.

VERHEYDEN, J.M., LEWANDOSKI, M., DENG, C., HARFE, B.D. and SUN, X. (2005). Conditional inactivation of Fgfr1 in mouse defines its role in limb bud establishment, outgrowth and digit patterning. Development 132: 4235-4245.

WEINSTEIN, M., XU, X., OHYAMA, K. and DENG, C.X. (1998). FGFR-3 and FGFR4 function cooperatively to direct alveogenesis in the murine lung. Development 125: 3615-3623.

WILKIE, A.O., PATEY, S.J., KAN, S.H., VAN DEN OUWELAND, A.M. and HAMEL, B.C. (2002). FGFs, their receptors, and human limb malformations: clinical and molecular correlations. Am J Med Genet 112: 266-278.

XU, X., WEINSTEIN, M., LI, C. and DENG, C. (1999). Fibroblast growth factor receptors (FGFRs) and their roles in limb development. Cell Tissue Res 296: 3343.

YU, K., XU, J., LIU, Z., SOSIC,D., SHAO,J., OLSON, E.N., TOWLER, D.A. and ORNITZ, D.M. (2003). Conditional inactivation of FGF receptor 2 reveals an essential role for FGF signaling in the regulation of osteoblast function and bone growth. Development 130: 3063-3074.

YU, S., ZHENG, L., TRINH, D.K., ASA, S.L. and EZZAT, S. (2004). Distinct transcriptional control and action of fibroblast growth factor receptor 4 in differentiating skeletal muscle cells. Lab Invest 84: 1571-1580.

ZHANG, X., IBRAHIMI, O.A., OLSEN, S.K., UMEMORI, H., MOHAMMADI, M. and ORNITZ, D.M. (2006). Receptor specificity of the fibroblast growth factor family. The complete mammalian FGF family. J Biol Chem 281: 15694-15700.

ZHAO, P., CARETTI, G., MITCHELL, S., MCKEEHAN, W.L., BOSKEY, A.L., PACHMAN, L.M., SARTORELLI, V. and HOFFMAN, E.P. (2006). Fgfr4 is required for effective muscle regeneration in vivo. Delineation of a MyoDTead2-Fgfr4 transcriptional pathway. J Biol Chem 281: 429-438. 


\section{Further Related Reading, published previously in the Int. J. Dev. Biol.}

See our recent Special Issue Placenta edited by Joan S. Hunt and Kent L. Thornburg at: http://www.ijdb.ehu.es/web/contents.php?vol=54\&issue=2-3

Competition for ligands between FGFR1 and FGFR4 regulates Xenopus neural development Masahiro Yamagishi and Harumasa Okamoto Int. J. Dev. Biol. (2010) 54: 93-104

Fibroblast growth factor signalling and regional specification of the pharyngeal ectoderm Nina Trokovic, Ras Trokovic and Juha Partanen Int. J. Dev. Biol. (2005) 49: 797-805

Targeted disruption of fibroblast growth factor receptor-1 blocks maturation of visceral endoderm and cavitation in mouse embryoid bodies Milan Esner, Jiri Pachernik, Ales Hampl and Petr Dvorak Int. J. Dev. Biol. (2002) 46: 817-825

Developmental expression of splicing variants of fibroblast growth factor receptor 3 (FGFR3) in mouse

C Wuechner, A C Nordqvist, A Winterpacht, B Zabel and M Schalling Int. J. Dev. Biol. (1996) 40: 1185-118

Expression of FGFR-4 mRNA in developing mouse tissues

$\mathrm{J}$ Korhonen, J Partanen and $\mathrm{K}$ Alitalo Int. J. Dev. Biol. (1992) 36: 323-329
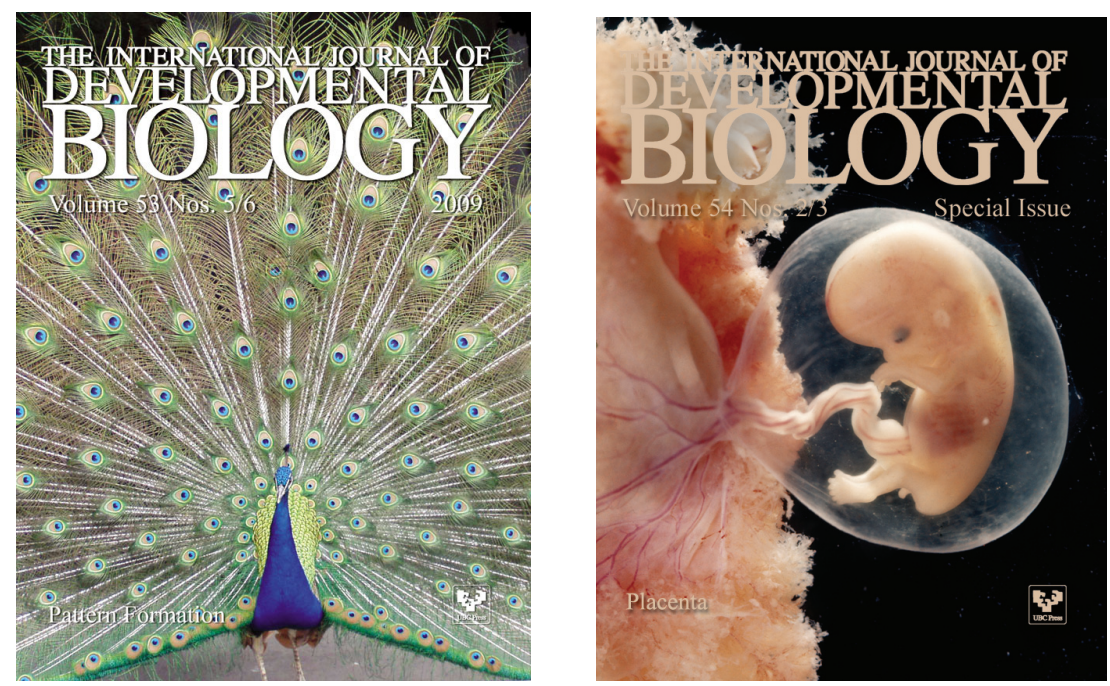

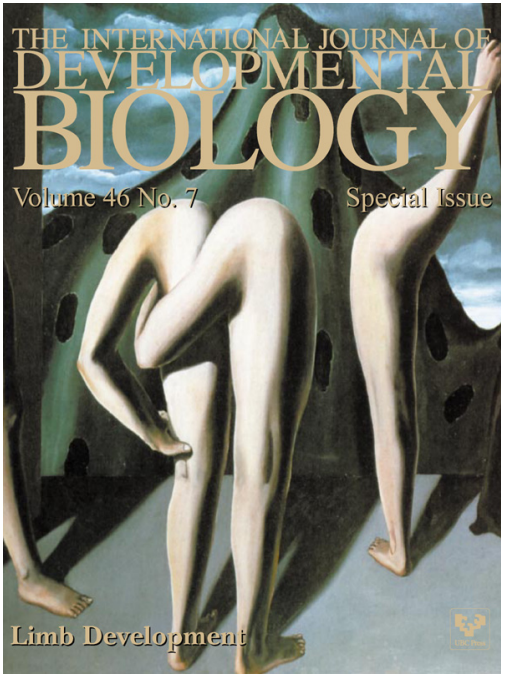

5 yr ISI Impact Factor $(2009)=3.253$

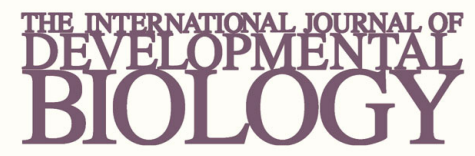

Volume 54 Nos. $6 / 7$

Special Issue
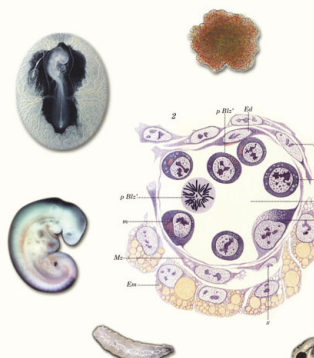

Developmental Hematopoiesis

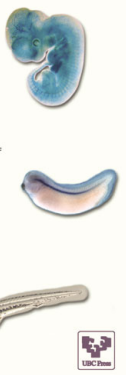

